\title{
Pakistan's Growth Spurts and Reversals: A Historical Perspective
}

\section{Rashid Amjad*}

\begin{abstract}
This paper takes a historical perspective to search for the major causes of Pakistan's stop-go growth cycles and come to the conclusion that, to varying degrees, the foreign exchange constraint provides a major explanation for these cycles of irregular economic growth in the country, particularly since the 1990s.
\end{abstract}

Keywords: Pakistan, macroeconomic management, foreign exchange, IMF

\section{JEL classification: F43.}

Pakistan's sixty-seven year history (1947-2014) has been characterized at regular intervals by spurts of relatively high economic growth followed by periods of low growth and stagnation. The recent prolonged recession accompanied by high inflation - stagflation - over the last five years (2008-13) has focused attention on the causes of these stop-go cycles and measures needed to break-out into a high and sustainable growth trajectory. The paper reviews the earlier and more recent explanations of these growth cycles. The aim is to help identify the critical factors that can explain these cyclical fluctuations especially those which act as a major constraint or bottleneck in the way of sustained economic growth. An important conclusion drawn from this historical analysis and review of earlier studies is that to varying degrees the foreign exchange constraint provides a major explanation for the stop-go cycles that have characterized economic growth in Pakistan. This is especially true of economic performance since the 1990s. These findings are especially relevant in the context of the main issue which this annual conference on the management of the Pakistan economy is addressing of increasing the country's export performance if it is to move to a path of higher and sustained growth.

While attention has been focused on explaining fluctuations in economic growth at regular intervals the paper further argues that this feature of the Pakistan economy should not draw away attention from an

\footnotetext{
* The author is Professor of Economics and Director, Graduate Institute of Development Studies, Lahore School of Economics. He has served as vice-chancellor Pakistan Institute of Development Economics (PIDE).
} 
equally important characteristic which is its display of overall resilience over the years and which has resulted in the economy growing on average at over 5 per cent over the entire period. Even during the downturns the economy has only in one year, 1951, had a negative growth rate. By analyzing the period of the recent stagflation (2008-2013) the paper shows that even during this slowdown the economy displayed both resilience and dynamism which had important implications for poverty reduction and growth of consumer demand in the economy. The paper therefore argues that it is not just important to analyze growth spurts and reversals but also the process of structural and dynamic changes which underlie these growth trends and their impact on important aspects of the economy.

\section{Pakistan's growth spurts and reversals}

Till recently Pakistan's growth performance was divided into periods of relatively high growth (the 1960s, 1980s, and 2002-07), which were also periods in which the country was under military rule, and periods of low growth (the 1950s, 1970s, 1990s, and 2008/09 onward), during which the country was under a civilian or democratically elected government.

The main explanation of this differing performance it has been argued, as by Amjad (1982) for the sixties, that in most cases, the economic downturns were triggered by the emergence of a foreign exchange constraint; this was eased considerably when military governments took over in situations where Western governments needed Pakistan's support, which the military in power were both better able and willing to provide.

It is, therefore, no coincidence that economic upturns and military rule coincided with major geopolitical developments: (i) the Cold War between the West and the former USSR in the 1960s (General Ayub Khan's government ruled from 1958 to 1969); (ii) the Soviet invasion and occupation of Afghanistan from 1979 to 1988, which was actively opposed by the US and other Western powers who provided rebel forces with arms and funds channeled through Pakistan (General Zia-ul-Haq's government ruled from 1977 to 1988), and (iii) the post-9/11 occupation of Afghanistan by US and NATO forces (supported by General Pervez Musharraf's government, which ruled from 1999 to 2008).

This division of Pakistan's economic performance into periods of military and civilian rule and the major explanation that the better performance of the former can be traced to large doses of external assistance is contested by McCartney (2011). First, he identifies a different breakdown of Pakistan's growth performance based on relative performance of one period as compared to the earlier period. Based on 
these results he identifies three episodes of growth - 1951/52 to 1958/59, $1960 / 61$ to $1969 / 70$, and $2003 / 04$ to $2008 / 09$ - and two episodes of stagnation $-1970 / 71$ to $1991 / 92$ and $1992 / 93$ to $2002 / 03$. The early period of civilian rule in the 1950s is seen as a period of higher economic growth and structural transformation in relation to the earlier pre-independence period. Interestingly, McCartney does not see a significant break in the growth performance of the economy between the periods of the Bhutto and Zia-ul-Haq military regimes, as compared to the period of growth in the 1960s. Indeed this episode of stagnation, so defined, continues all the way to 1991/92, well after the end of the Zia period in 1989 and the advent of civilian rule. This episode is followed by another period of what would be even relatively deeper stagnation as compared to the earlier period.

Second, and more importantly, McCartney finds no credible evidence for attributing Pakistan's episodes of growth to increases in foreign aid inflows or to shocks emerging from the external economy. His view is that, even when Western aid was cut off or slowed down, Pakistan managed to turn to other countries such as China (after 1965) or Saudi Arabia and other donors in more recent years.

McCartney's view is that the role of the state, rather than external factors, was mainly responsible for Pakistan's economic growth spurts and reversals. He argues that the state creates conditions through its economic policies (as it did, for example, by restricting imports after the Korean War boom in the early 1950s), which result in high profits, and then channels credit to the private sector to invest in these sectors or industries (as in the 1950s and 1960s as part of an import substitution industrial strategy). He also finds no systematic relationship between economic growth and external finances or economic liberalization.

While one would fundamentally agree with McCartney on the critical role of the state in spurring episodes of growth or development, he perhaps underplays the role of rising foreign resource inflows in breaking or at least easing the foreign exchange constraint that Pakistan has periodically faced. While, with hindsight, Amjad (1982) may have overemphasized this role, it would appear that McCartney takes an extreme position in almost completely ignoring it.

There are, however, some important lessons to draw from McCartney's analysis. If the role of the state is critical, as he argues, in creating conditions that are conducive to investment and growth, then clearly after the 1950s the military governments were relatively more successful in creating such conditions than their civilian counterparts. 
More recently, the World Bank (2013) and López-Cálix, Srinivasan, and Waheed (2012) have analyzed growth patterns in Pakistan for the period 1960-2010. They identify eight episodes of high growth (more than 5 percent) spanning 28 years in all with an annual average of 7 percent; the longest spurt extends over six years from 1978 to 1983. They also identify eight episodes of low growth (less than 5 percent) spanning 22 years in all with an average growth rate of 3.3 percent; here, the longest period lasted seven years from 1997 to 2003.

Relying on these results and other studies, the World Bank (2013) points to increasing episodes of short growth acceleration as well as the fact that growth expectations (at least in its view) are becoming increasingly less optimistic. Since various studies have argued that developing countries need growth acceleration to stretch over a period of at least eight years in order to move onto a higher and sustained growth path, the Bank's findings are clearly worrying.

The World Bank draws two major explanations from its analysis: (i) external shocks (i.e., those resulting in increased foreign resource inflows) produce growth accelerations that fizzle out (when these inflows decline), and (ii) economic reforms remain a significant predictor of sustained accelerations.

There are three important conclusions that we can draw from the World Bank's analysis. First, it reinforces the earlier view that the availability of external resources has played an important role in generating episodes of economic growth and, therefore, in partly explaining the better economic performance of military regimes who had easier access to such resources during their rule.

The second is that economic reforms increase the efficiency and productivity of the economy by fostering foreign and domestic competition as well as through measures leading to better governance and economic management. This occurs in part when the arbitrary interference exercised through government controls is reduced and plays an important role in accelerating economic growth. Again, there is evidence that military governments have been far more committed to and successful in implementing such reforms compared to their civilian counterparts.

The third that the potential of the economy to accelerate economic growth is over time being reduced. This would appear to be the result of the economy becoming structurally more inefficient and hence the reforms needed become more severe and thus more challenging to implement. 


\section{Explaining growth cycles: Identifying binding constraints on sustained growth}

To bring out somewhat more sharply the critical factor or factors that can act as a constraint on economic growth in developing countries we turn to the traditional models that identified these constraints and showed how these act as major bottlenecks or gaps to economic growth and development. These models extended the traditional savings gap to other variables, the most important of which was identified as the foreign exchange gap in the two-gap models. This was because foreign exchange was critically needed to import machinery which could not be produced domestically as well as other imported inputs and the demand for these could not be met by the country's meager export earnings. These models were then further extended to include the shortage of skilled labor ("skills gap") or lack of public resources to fund essential physical and social infrastructure ("fiscal gap"). Major pioneering studies of the two- and three-gap model include those of Chenery and Strout (1966) and McKinnon (1964).

An important finding of these studies was that the emergence of these bottlenecks or constraints could vary depending on the stage of economic development as well as differ amongst countries at different levels of development. These exercises also brought out the need or importance of foreign aid or assistance to overcome these gaps as well as to help prioritize the use of such aid made available including the quantum of aid.

More recently the concept of binding constraints on development have been used to prioritize needed reform measures to overcome these constraints through a "growth diagnostic" exercise (see Hausmann, Rodrik, and Velasco, 2005). An important objective of these exercises have also been to "develop a better understanding of how the binding constraints on economic activity differ from setting to setting," and how this understanding can be used to "derive policy priorities, in a way that uses efficiently the scarce political capital of reformers." (Ibid, p.1).

In the case of Pakistan two studies, one covering the period 197093 (Iqbal, 1995) and the second covering the period 1988-2008 (Panel of Economists (2010) are discussed in the context of the binding constraints to growth during these periods.

Iqbal (1995) in his study sets up a three gap model to determine the main macroeconomic constraints to economic growth of Pakistan. These are identified as: (a) foreign exchange constrained growth; (b) savingsconstrained growth; and (c) fiscal constrained growth. By estimating 
potential output, capacity utilization and natural rate of unemployment the study comes up with an estimate of a plausible growth rate in potential output of 5.7 per cent for Pakistan. Also his estimates show that the Pakistan economy was working at full capacity until 1977 after which it started declining and reached 87 per cent in 1992-93. He does caution, however, that since these estimates of potential output are based on open unemployment rate these estimates may not be a good indicator of potential output and capacity utilisation in Pakistan's case.

His findings are somewhat difficult to interpret in terms of the relative importance of each of these constraints over the time period as his model primarily identifies policy measures which would ease these three constraints that keep the economy working below its full potential. His results based on regression analysis covering the period 1977-92 show that in the face of a foreign exchange constraint, real devaluation and growth in foreign demand ease this constraint and allow an accelerated rate of growth of potential output. In contrast, in the face of a savings constraint, real devaluation and increased foreign demand reduce potential output growth. Finally, the result of the fiscal constraint equation shows that as this constraint is eased, it improves potential output through higher capacity utilization.

The more recent study by the Panel of Economists (Pakistan, Planning Commission, 2010) ${ }^{1}$ perhaps illustrates better how the foreign exchange and savings constraints have acted as a bottleneck to the economy realizing a growth rate which would result in the productive absorption of the growth in the labor supply.

The interesting result of the Panel of Economists study over the twenty year period 1988-2008 is that given its current savings rate to finance investment and without getting into a balance of payment crisis (through running an unsustainable current account deficit) the sustainable rate of growth of the economy is 5.45 per cent. This calculation is based on estimating the availability of total resources (national savings plus foreign savings taken as the current account deficit) over the 1988-2008 period and multiplying it with incrementalcapital-output ratio (ICOR) estimated at approximately 4.0. The study then calculates the rate of job creation by using the estimated growth rate of 5.45 per cent and multiplying it by the employment-elasticity of output

\footnotetext{
${ }^{1}$ The study was conducted by Dr. Naved Hamid and Dr. Azam Chaudhry of the Lahore School of Economics both of whom were members of the Panel of Economists.
} 
estimated at 0.465 and comes up with an annual employment gap of 0.46 per cent given the growth rate of the labor force of 2.95 per cent. ${ }^{2}$

The conclusion that the Panel of Economists study therefore reaches is that a "fascinating" imbalance exists for at the current rate of sustainable growth of 5.45 per cent, which is also close to the average actual growth rate of 5.05 per cent over the last twenty years, the rate of unemployment would increase by 0.46 per cent per annum and based on the actual average growth rate of 5.05 per cent (by 0.63 per cent). Also, importantly their results show that if the unemployment rate is to be kept from increasing the economy would be facing a 3.25 per cent resource gap per year which "being unsustainable would sooner or later result in a balance of payment crisis" (ibid, p.26).

\section{Foreign Exchange Constraint as the biding constraint in the last twenty five years (1988-2013)}

In order to further illustrate the importance of the foreign exchange constraint we have shown separately the growth pattern over 1980-2013 and the foreign exchange reserves ${ }^{3}$ over this period. Taking the latter to represent the vulnerability of the foreign exchange situation in terms of capacity to meet foreign exchange obligations (payment for imports, repatriation of profits and debt repayment), Figure 2 clearly shows that, in most years, the foreign exchange reserve situation was below the safe average normally taken as a minimum of three months of reserves in term of import requirements, and in fact needed to be much higher to take into account debt repayments which had increased substantially during this period. The years between 1986 and 2000, when the economy drastically slowed down, is also reflected in the very low foreign exchange reserves during these years. Similarly the years of high economic growth from 2002 to 2007 also coincide with a very significant improvement in the foreign exchange reserves which rise sharply after 2000. This increase was due initially to a loan injection from the IMF and then a dramatic increase in remittances and repayments being reduced due to the rescheduling of debt by the major donors post-9/11. But again the reserve situation deteriorates due to sharp increases in oil and commodity prices, leading to a drastic decline in foreign exchange reserves which reach critical levels in 2008.

\footnotetext{
${ }^{2}$ The study also uses alternative estimates of the ICOR (3.65 and 4.0) but these do not change the main findings of the study.

${ }^{3}$ The foreign exchange reserves for a particular year are taken as the average of the reserves held in June and December.
} 
Figure 1: Economic Performance 1980-2013

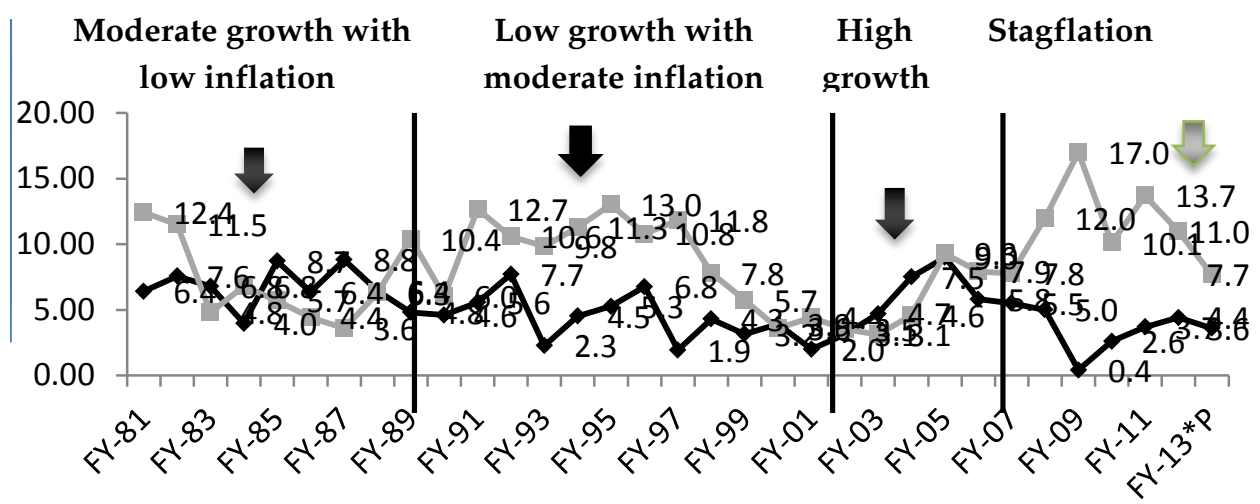

Source: Pakistan Economic Survey (Different Years)

Figure 2: Foreign Exchange Reserves in weeks of imports (1980-2012)

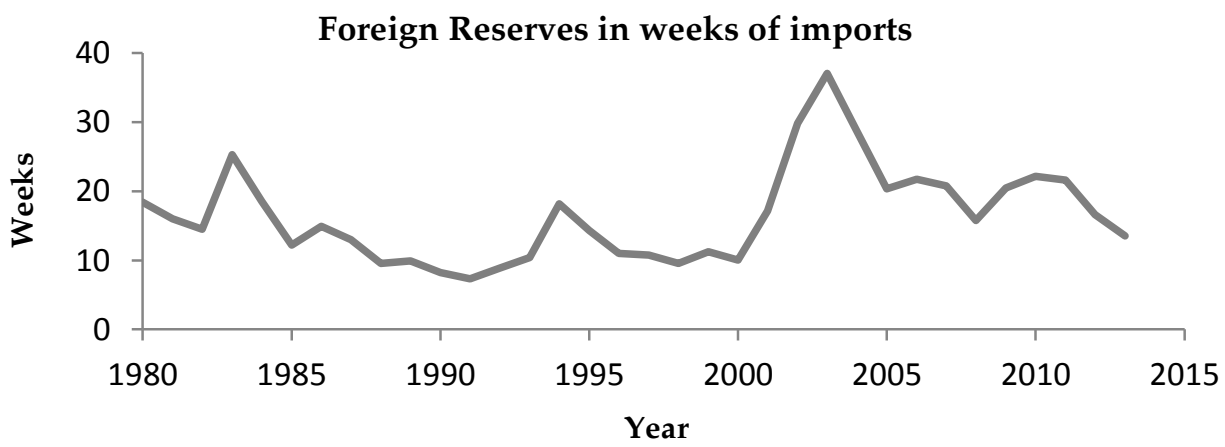

Source: Pakistan Economic Survey (2013-14))

This vulnerability of the economy in terms of available foreign exchange reserves is to our mind best illustrated by the frequent recourse to the IMF over this period primarily, as most studies have shown, to obtain funding for resolving the balance of payment crisis (see Hussain, 2002), Over this period, from 1988 until 2013, Pakistan entered into as many as 11 agreements with the IMF (December, 1988 (two), September, 1993, February 1994, December, 1995, October, 1997 (two), November, 2000, December, 2001, November, 2008 and July, 2013) primarily to avoid default on debt repayments (especially to the IMF) and meeting import requirements.

While each of these episodes requires careful study as to the nature and cause of the crisis which led to the recourse to the IMF, what can be safely said is that in most cases it was the result of a balance of payment crisis and a fear of debt default. Also, the resulting agreements with the IMF have required steps to compress aggregate demand and 
slow down the growth of the economy. This happened in the most extreme form in 2008 when, after the signing of an agreement with the IMF in November 2008, the growth rate drastically fell from over 5 per cent in 2007-08 to 0.4 per cent in 2008-09. This is a strong illustration of how the emergence of a severe foreign exchange constraint and fear of default can sharply cut down the growth rate.

The results of the two earlier studies, Iqbal (1995) and Panel of Economists (2010) as well as this illustration of the relationship between economic growth and the vulnerable foreign exchange reserve situation, all point to the fact that at least in the short- to medium- term the economy is working below or well below its existing capacity which of course negatively results also on its long term growth prospects.

These results also show the importance of studying not just the medium to long term growth cycles through which Pakistan has passed but also the importance of short- to medium term macroeconomic management of the economy so as to predict the emergence of the foreign exchange constraint as well as how best to manage it. What has frequently happened in the past is that economic managers and policy makers have waited until the situation has become desperate and then have turned to the IMF to bail out the economy which resulted, due to strong measures needed to restore macroeconomic stability, in a much steeper decline in the growth rate than would otherwise have been required. This is not to suggest that if one had not gone to the IMF such cuts in growth would not have taken place. Indeed quite the opposite. The hidden assurance that the IMF would bail you out makes you take this dangerous route.

It is also somewhat ironic that after having signed the loan agreements with the IMF and got the first tranche of the loan (which also helped to get loans from other donors and IFIs) in all cases starting in 1988 until 2000, none of the agreements were successfully completed and most were abandoned fairly soon after they were signed. This was due to the fact that the government could not carry out the economic reforms they had agreed to with the IMF mainly due to lack of political will and fear of public backlash (against raising prices of public utilities, reducing subsidies and expanding the tax net). It was therefore not long that in the absence of needed reform measures the foreign exchange constraint once again re-appeared and the government once again went to the IMF which obliged with even tougher agreed measures and which led to the loan agreement again being abandoned. There are important lessons here both for policy makers as well as the IMF. 


\section{Resilience during the economic downturn: 2007/08 to 2012/13}

This rather depressing scenario of poor economic management, the resulting poor growth performance of the economy and the need to tackle it should not, however, detract from the fact that despite these failings the Pakistan economy over the years has displayed resilience and dynamism including during the downturns in economic growth. To illustrate this dynamism we analyze in some detail Pakistan's economic performance during the years of low growth and high inflation from $2007 / 08$ to 2012/13 in terms of some key economic variables.

The dynamism of Pakistan's economy in the five years from 2008 until 2013 can be seen through the movement and performance of some key economic variables:

- Despite low economic growth, consumption levels have grown faster. This reflects not only the fact that a larger portion of national output is being consumed rather than invested, but also that a large part of remittances and income generated from the undocumented economy (estimated at 80 to 90 percent of the documented economy) (see Kemal \& Qasim, 2012) are driving these higher levels of consumption.

- The high levels of consumption are reflected in the high profitability ratios of food industries quoted on the Karachi Stock Exchange over the last five years as well as the high profits of foreign companies such as Pepsi, Unilever, and Nestle whose profits and sales have grown between 15 and 20 percent per annum during this period.

- Poverty levels have declined at least up until 2010/11 (for which data are available). Poverty levels based on a 2,350 caloric intake (an income of around PRs 11,000 per month for a six-person household or Rs 56 per day in 2010/11) declined from over 30 percent in 2000/01 to around 17.2 percent in 2007/08 and further to 12.4 percent in 2010/11. The latest data have also been examined by the World Bank, which, after taking into account some of the criticism leveled against the 2010/11 estimates, concluded that poverty levels had indeed fallen (although they may be slightly higher if measured by a higher poverty line) (Newman, 2013).

- There is an emerging middle class whose share of the total number of households increased between 2007/08 and 2010/11 from 18.8 percent to 24.2 percent, based on a strict definition of the middle class, or from 34.6 to 42.9 percent, based on an expanded definition (see Nayab, 2011, 2013). An Asian Development Bank study (2010) has shown that, in 2005, the percentage of total households living on US\$2-4 (PPP) a day in Pakistan was around 32.94 percent (compared to 20.45 percent in 
India the same year). The proportion living on US\$ 4-10 (PPP) was 6.56 in Pakistan compared to 4.15 percent in India. The annual sale of around 1.7 million motorcycles a year in 2013 points to an emerging middle class as do the rising sales of many consumer durables.

- The real wages of agricultural workers increased from 2007 to 2010, based on the reports of the Agriculture Price Institute. The Labour Force surveys also point to an increase in wages in the agriculture and services sectors, although they declined in construction (see Amjad, 2012).

- Pakistan has a very high tele-density: in November 2013, the number of subscribers to mobile telephones was 132 million out of a population of 180 million.

\section{Key factors contributing to the resilience and dynamism of the economy during the downturn of 2008-13}

Explaining these positive developments at a time when the economy was going through a period of severe stagflation in terms of low economic growth and until recently double digit inflation is a challenging task and the author has tried to identify some of the factors in a recent study (Amjad, 2013). The major explanations appear to be the following though it must be readily admitted that there still remains a considerable schism between these explanations and the macroeconomic situation as provided in the official data, which must perforce be considered as sacrosanct (unless officially altered).

- First is the massive increase in remittances which not only increased significantly during the boom years from 2002-2008 but also continued to sharply increase in the stagflation years of 2008-2013. They increased to around USD 6.5 billion in 2007/08 and nearly USD14 billion in 2012-13 which was around 6 per cent of GDP in the latter year.4 This could have been an important factor in increasing consumer demand, although it must be admitted that the multiplier effects on the economy in terms of increased production levels are not sufficiently captured in the macroeconomic or sectoral data (unless they led to an increase in imports).

- Second, the youth bulge with the young entrants possess higher levels of education and skills than the existing work force having generated for themselves self-employment opportunities including a large part in the small and informal sector which again may not be captured in the official statistics.

\footnotetext{
${ }^{4}$ Pakistan Economic Survey 2013-14 for remittances in different years.
} 
- Third, the increasing entry of educated women into both selfemployment (eg. dress making including fashionable clothing, food items) catering to a rising middle class and service sector jobs especially in major urban centers which again may be only partially captured in both the economic as well as the labor force statistics.

- Fourth, at least in the initial years, from 2008 to 2009, a massive increase in support prices for wheat from Rs. $450 / 40 \mathrm{~kg}$ in 2007 to Rs. $950 / 40 \mathrm{~kg}$ in 2008 as well as increases in prices of other items such as rice and milk and livestock have had a favorable impact on rural incomes and correspondingly on rural wages and may also explain the rise in demand for food products, motorcycles and semi-luxury items like creams and hand lotions and make-up items emanating from rural areas.

- Finally, rapid urbanization and the growth of mega cities have generated job opportunities and rising incomes especially for those in service sector jobs.

\section{Conclusions}

The main conclusion of the paper is that the Pakistan economy has not performed to its potential and this reflects both poor short- to medium term macro-economic management and the emergence of serious structural constraints which have resulted amongst others in recurring balance of payment crisis. The country has been fortunate in that favorable external developments in the form of a manifold increase in remittances and some positive internal developments have kept the economy afloat and in the process generated sufficient dynamism such that extreme poverty has continued to decline.

A glaring message which does emerge from our historical analysis is that a binding constraint has been the foreign exchange constraint which especially in the last two and a half decades has been responsible for the economy's poor performance. While the manifold increase in remittances in the last decade and a half need to be welcomed they cannot substitute for Pakistan's continuing poor export performance. This again is an area which has been analyzed many times earlier and with hindsight on what has worked and not worked. This conference, with its focus on improving Pakistan's export performance, offers us an opportunity to come up with workable and doable policy solutions to help remove and initially ease the foreign exchange constraint which continues to throttle economic growth. 


\section{References}

Ahmed, V., \& Amjad, R. (1984). The management of the Pakistan economy 1947-82. Karachi, Pakistan: Oxford University Press.

Amjad, R. (1982). Private industrial investment in Pakistan 1960-70. Cambridge, UK: Cambridge University Press.

Amjad, R. (2012). Stagflation, labour market impact and the poverty puzzle in Pakistan: A preliminary analysis. Lahore Journal of Economics [Special Edition], 17, 51-71.

Amjad. R. (2013). Economic management under Musharraf and Coalition rule: Key lessons for Sustainable Growth, in R. Amjad \& S. J. Burki (Eds.), Pakistan: Moving the economy forward. Lahore, Pakistan: Lahore School of Economics.

Asian Development Bank. (2010). Key indicators for Asia and the Pacific 2010. Manila, The Philippines: Author.

Chenery, H. \& Strout, A. (1966), Foreign Assistance and Economic Development, American Economic Review 56: 679-733

Hausmann, R., Rodrik, D. \& Velasco, A. (2005). Growth Diagnostics. John F. Kennedy School of Government, Harvard University, Cambridge (revised March 2005.

Hussain, I. (2002). Pakistan and the IMF: 1988-2002 - A case study. Paper presented at the International Expert Workshop organized by the German Foundation for Development (DSE) at Berlin on July 1-2, 2002.

Iqbal, Z. (1995). Constraints to economic growth of Pakistan: A three gap approach. The Pakistan Development Review 34:4 Part III (Winter 1995) pp.1119-1133

Kemal, M. A., \& Qasim, A. W. (2012, November). Precise estimates of the informal economy. Paper presented at the 28 $8^{\text {th }}$ Annual General Meeting of the Pakistan Society of Development Economists, Islamabad. 
López-Cálix, J. R., Srinivasan, T. G., \& Waheed, M. (2012). What do we know about growth patterns in Pakistan? (Policy Paper Series on Pakistan PK 05/12). Washington, DC: World Bank.

McCartney, M. (2011). Pakistan: The political economy of growth, stagnation and the state, 1951-2009. Abingdon, UK: Routledge.

McKinnon, R. (1964) Foreign Exchange Constraints in Economic Development and Efficient Aid Allocation, The Economic Journal, Vol. 74, No. 294 (June 1964), pp. 388-409

Nayab, D. (2011). Estimating the middle class in Pakistan. Pakistan Development Review, 50(1), 1-28.

Nayab, D. (2013). Youth bulge and the middle class (Mimeo). Islamabad: Pakistan Institute of Development Economics.

Newman, J. (2013). Recovering strong positive trends in poverty and opportunity (Pakistan Policy Note No. 5). Washington, DC: World Bank.

Pakistan, Ministry of Finance. (2014). Pakistan economic survey 2013-14. Islamabad: Author.

Pakistan, Planning Commission. (2010) Final report of the Panel of Economists: Medium-term development imperatives and strategy for Pakistan. Islamabad, Pakistan: Author

World Bank. (2013). Finding the path to job-enhancing growth: A country economic memorandum (Report No. 75521-PK). Washington, DC: Author. 